NASA/TM-2006-214113

\title{
Validating Coherence Measurements Using Aligned and Unaligned Coherence Functions
}

Jeffrey Hilton Miles

Glenn Research Center, Cleveland, Ohio 
Since its founding, NASA has been dedicated to the advancement of aeronautics and space science. The NASA Scientific and Technical Information (STI) Program Office plays a key part in helping NASA maintain this important role.

The NASA STI Program Office is operated by Langley Research Center, the Lead Center for NASA's scientific and technical information. The NASA STI Program Office provides access to the NASA STI Database, the largest collection of aeronautical and space science STI in the world. The Program Office is also NASA's institutional mechanism for disseminating the results of its research and development activities. These results are published by NASA in the NASA STI Report Series, which includes the following report types:

- $\quad$ TECHNICAL PUBLICATION. Reports of completed research or a major significant phase of research that present the results of NASA programs and include extensive data or theoretical analysis. Includes compilations of significant scientific and technical data and information deemed to be of continuing reference value. NASA's counterpart of peerreviewed formal professional papers but has less stringent limitations on manuscript length and extent of graphic presentations.

- TECHNICAL MEMORANDUM. Scientific and technical findings that are preliminary or of specialized interest, e.g., quick release reports, working papers, and bibliographies that contain minimal annotation. Does not contain extensive analysis.

- CONTRACTOR REPORT. Scientific and technical findings by NASA-sponsored contractors and grantees.
- CONFERENCE PUBLICATION. Collected papers from scientific and technical conferences, symposia, seminars, or other meetings sponsored or cosponsored by NASA.

- SPECIAL PUBLICATION. Scientific, technical, or historical information from NASA programs, projects, and missions, often concerned with subjects having substantial public interest.

- TECHNICAL TRANSLATION. Englishlanguage translations of foreign scientific and technical material pertinent to NASA's mission.

Specialized services that complement the STI Program Office's diverse offerings include creating custom thesauri, building customized databases, organizing and publishing research results ... even providing videos.

For more information about the NASA STI Program Office, see the following:

- Access the NASA STI Program Home Page at http://www.sti.nasa.gov

- E-mail your question via the Internet to help@sti.nasa.gov

- Fax your question to the NASA Access Help Desk at 301-621-0134

- Telephone the NASA Access Help Desk at 301-621-0390

- Write to:

NASA Access Help Desk

NASA Center for AeroSpace Information 7121 Standard Drive

Hanover, MD 21076 
NASA/TM-2006-214113

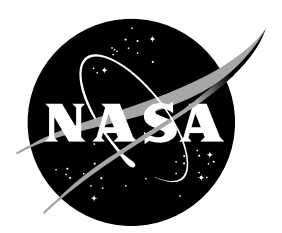

\section{Validating Coherence Measurements Using Aligned and Unaligned Coherence Functions}

Jeffrey Hilton Miles

Glenn Research Center, Cleveland, Ohio

Prepared for the

44th Aerospace Sciences Meeting and Exhibit

sponsored by the American Institute of Aeronautics and Astronautics

Reno, Nevada, January 9-12, 2006

National Aeronautics and

Space Administration

Glenn Research Center 
Trade names or manufacturers' names are used in this report for identification only. This usage does not constitute an official endorsement, either expressed or implied, by the National Aeronautics and Space Administration.

This work was sponsored by the Fundamental Aeronautics Program at the NASA Glenn Research Center.

Available from

NASA Center for Aerospace Information 7121 Standard Drive

Hanover, MD 21076
National Technical Information Service 5285 Port Royal Road Springfield, VA 22100 


\title{
Validating Coherence Measurements Using Aligned and Unaligned Coherence Functions
}

\author{
Jeffrey Hilton Miles \\ National Aeronautics and Space Administration \\ Glenn Research Center \\ Cleveland, Ohio 44135
}

\begin{abstract}
This paper describes a novel approach based on the use of coherence functions and statistical theory for sensor validation in a harsh environment. By the use of aligned and unaligned coherence functions and statistical theory one can test for sensor degradation, total sensor failure or changes in the signal. This advanced diagnostic approach and the novel data processing methodology discussed provides a single number that conveys this information. This number as calculated with standard statistical procedures for comparing the means of two distributions is compared with results obtained using Yuen's robust statistical method to create confidence intervals. Examination of experimental data from Kulite pressure transducers mounted in a Pratt \& Whitney PW4098 combustor using spectrum analysis methods on aligned and unaligned time histories has verified the effectiveness of the proposed method. All the procedures produce good results which demonstrates how robust the technique is.
\end{abstract}

\section{Nomenclature}

$D \quad$ delay time,sec

$d_{1} \quad$ Yuen squared standard error of the aligned coherence values

$d_{2} \quad$ Yuen squared standard error of the unaligned coherence values

$f_{c} \quad$ upper frequency limit, $f_{c}=1 / 2 \Delta t=r / 2, \mathrm{~Hz} .(24000 \mathrm{~Hz}$.

$G_{x x}(f), G_{x x}(f)$ auto-spectra

$G_{x y}(f)$ cross-spectrum

$j \quad$ positive imaginary square root of $-1, \sqrt{-1}$

$L_{y} \quad$ number of frequencies, $f_{c} / \Delta f=N / 2(2048)$

$n$ number of coherence values used to compute $\Lambda$

$N 1 C O R R$ corrected rotor speed, rpm

$n_{d} \quad$ number of disjoint (independent) segments used in spectra estimates of PW4098 test data, $n_{d}=$ $B_{e} T_{\text {total }}=234$

$n_{k}, n_{\ell}$ random time series

$n_{s} \quad$ number of segments

NP segment length, number of data points per segment (4096)

$r \quad$ sample rate,samples/sec. (48000)

$s(t) \quad$ time history

$t$ time, sec.

$T_{\text {total }}$ total record length,sec. $(\approx 20 \mathrm{sec}$.

$t_{Y u e n}$ the $1-\alpha / 2$ quantile of Student's t distribution with $\hat{\nu}_{Y \text { uen }}$ degrees of freedom

$T_{d}(i) \quad$ record length of segment $i, \frac{T_{\text {total }}}{n_{d}}, \frac{N P}{r}$,sec. $T_{d}=\frac{N P}{r}=4096 / 48000=0.08533$ sec.

$\bar{X}_{t 1} \quad$ sample trimmed mean of aligned coherence values

$\bar{X}_{t 2} \quad$ sample trimmed mean of unaligned coherence values

$X(f) \quad$ Fourier transform of $\mathrm{x}(\mathrm{t})$

$x(t) \quad$ signal $\mathrm{x}$ time history 
$Y(f) \quad$ Fourier transform of $\mathrm{y}(\mathrm{t})$

$y(t) \quad$ signal y time history

Subscripts

1.2 locations 1 and 2

$i \quad$ running segment index

Symbols

$\alpha \quad$ probability

$\Delta f \quad$ frquency step, $1 / T_{d}, \mathrm{~Hz}$. (11.718)

$\Delta t \quad$ sampling interval, $1 / r(1 / 48000)$, sec.

$\eta \quad$ evidence dimension

$\hat{\gamma}_{r_{k} r_{\ell}}^{2}(f)$ estimated magnitude squared coherence (MSC) function

$\gamma_{x y}^{2}(f)$ magnitude squared coherence function

$\Lambda \quad$ confidence test parameter

$\mu \quad$ mean value

$\hat{\nu}_{Y \text { uen }}$ Yuen number of degrees of freedom

$\nu \quad$ degrees of freedom, $\nu=2(n-1)$

$\sigma \quad$ variance

Superscripts

* complex conjugate

\section{Introduction}

Sensor validation in the broadest sense is related to reliability. One must be able to determine that a sensor is or is not providing the correct signal. In addition, if the signal changes one would like a test that was able to distinguish between a sensor degradation from normal operating performance, total sensor failure, and changes in the signal due to changes in the signal source unrelated to the sensor. This document shows how conventional statistical methods ${ }^{1-3}$ and a robust statistical method developed by Yuen $^{4-6}$ can be applied to identify Kulite sensor degradation or Kulite sensor failure, and separate these changes from changes in the signal. The question examined here is given two combustor Kulite pressure transducers how can the sensor signals be used to validate dynamic signal measurements. The sensor analysis scheme discussed herein was developed as part of a study of core noise from a Pratt \& Whitney turbofan engine by Miles. ${ }^{7}$

The goals in analyzing the sensor data are:

1. to minimize Type I errors, i.e. false alarms, and Type II errors, i.e. unable to detect an invalid signal when one occurs.

2. to provide a rapid decision as to the existence of a faulty condition.

3. to provide a test that does not depend on steady state (sample) statistics but rather statistics calculated from a time varying process.

4. to provide a test that validates a pair of measurement devices.

5. to provide a test that produces a single number that provides this information.

Sensor validation plays an important role in automatic control and system monitoring within safety critical systems such as the aerospace and nuclear industry.

A sensor validation scheme based on the auto-associative neural network is discussed by T.-H. Guo and J. Musgrave $^{8}$ for application to detect and recover from sensor faults in a simulation of the Space Shuttle Main Engine (SSME) control system. They reconstruct one or more lost sensor data using a redundant sensor set. Real time intelligent sensor validation using a Bayesian network for the detection of a fault in a set of sensors and a Bayesian network to isolate the faulty sensors discussed by Ibargüengoytia Ref. ${ }^{9}$

Another integrated sensor validation and fusion scheme is discussed by Wellington, Atkinson, and Sion Ref. ${ }^{10}$ One limitation of these methods is that validation of an individual measurement device is disregarded and system level validation is emphasized. 
The following papers focus on individual measurement device validation through examination of patterns created by different sensor failures.

Validation of thermocouple sensor signals based on their signal patterns has been discussed by Yung. ${ }^{11}$

Using the sensor signal from a dynamic process to validate a sensor has been discussed by Himmelblau and Bhalodia. ${ }^{12}$

A novel approach based upon using wavelet transforms to characterize the sensor signal in the time and frequency domain has been proposed by Ma, Zhang and Yan. ${ }^{13}$

A sensor fault detection and identification (FDI) scheme based on parameter estimation by means of an extended Kalman filter (EKF)is presented by Del Gobbo. ${ }^{14}$

Applying signal processing methods to signals from a single sensor for validation has been suggested by Amadi-Echendu. ${ }^{15}$

The paper is organized as follows. The theoretical background will be outlined next. Then the experimental results will be discussed. Finally, the conclusions are given.

\section{PW4098 Engine at C-11 Stand for EVNRC Phase 2 Tests}

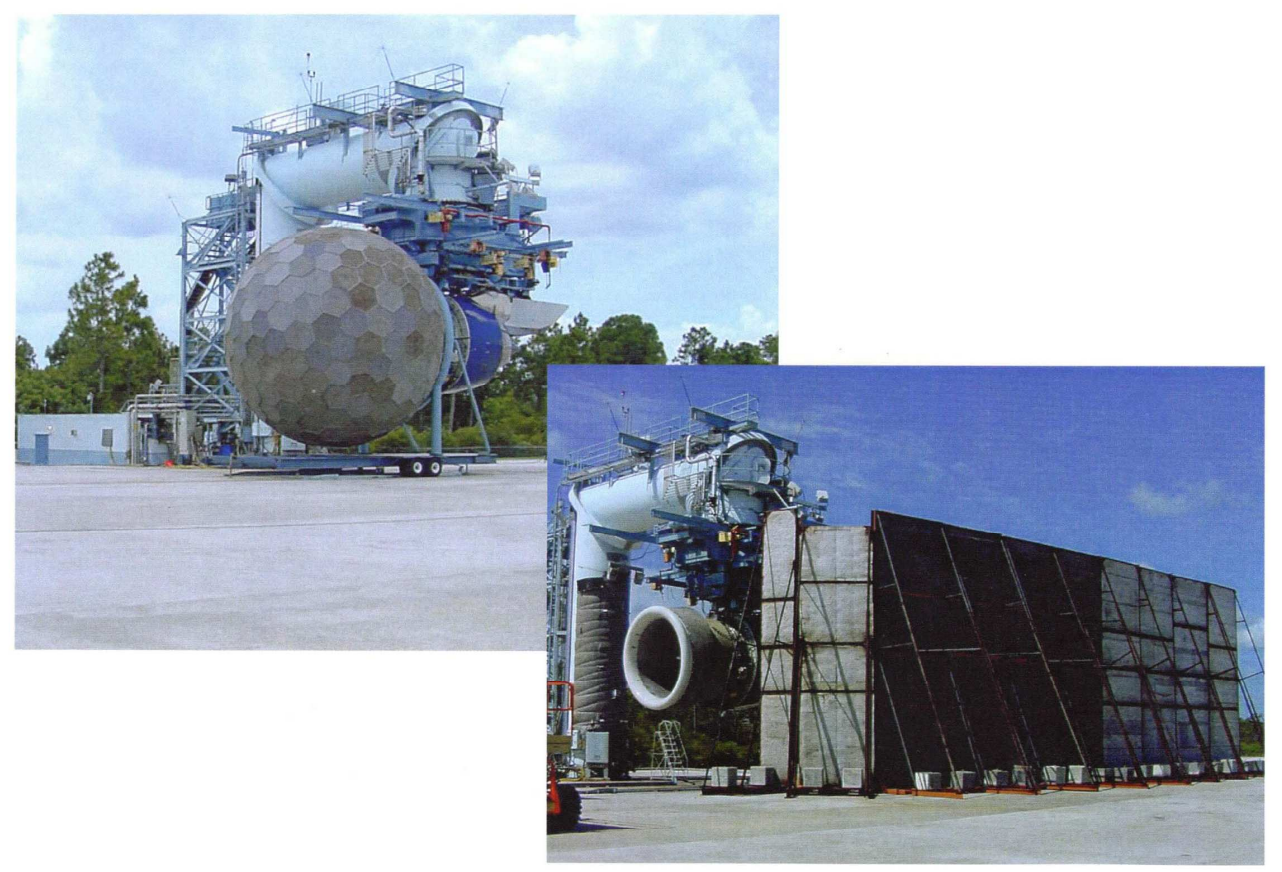

Figure 1. Pratt \& Whitney test stand C11, West Palm Beach Florida, with PW4098 engine and attached acoustic inflow control device also with and without aft acoustic barrier walls for EVNRC Phase 2 tests.

\section{Background}

The details of the aligned and unaligned coherence method are given by Miles. ${ }^{7}$ Only an outline will be presented herein. The magnitude squared coherence (MSC) function, $\gamma_{x y}^{2}(f)$ calculated using the complex cross-spectral density, $G_{x y}(f)$, and two auto-spectral densities at frequency f $G_{x x}(f)$ and $G_{y y}(f)$ is defined by: 


$$
\gamma_{x y}^{2}(f)=\frac{\left|G_{x y}(f)\right|^{2}}{G_{x x}(f) G_{y y}(f)}
$$

The MSC function is discussed by Bendat and Piersol, ${ }^{16-18}$ and Carter. ${ }^{19}$ The MSC function identifies the degree of coupling between two time series. The normalization used insures the coherence has values between zero (the absence of correlation) and one (complete correlation).

The MSC function estimation procedure used herein is based on signal processing algorithms developed by Stearns and David. ${ }^{20}$ They refer to their spectral-estimation code as using a periodogram averaging method. Many hardware and software spectrum analysis systems use similar methods. The following set of equations will be used to discuss the calculation of the estimated MSC function by the periodogram averaging method. The estimated MSC function calculated using $n_{d}$ weighted Fourier transforms $\left.X \hat{(} f\right)_{i}$ and $Y(f)_{i}$ based on a segment record length $T_{d}$ is defined by

$$
\begin{aligned}
w(\tau) & =\left(1-\frac{|\tau|}{T_{d}}\right) \\
\hat{x}(\tau) & =w(\tau) x(\tau) \\
\hat{y}(\tau) & =w(\tau) y(\tau) \\
\hat{X}_{i}(f) & =\int_{0}^{T_{d}(i)} \hat{x}(\tau) \exp (-j 2 \pi f \tau) d \tau \\
\hat{Y}_{i}(f) & =\int_{0}^{T_{d}(i)} \hat{y}(\tau) \exp (-j 2 \pi f \tau) d \tau \\
\hat{\gamma}_{x y}^{2}(f) & =\frac{\left|\sum_{i=1}^{n_{s}} \hat{X}_{i}(f) \hat{Y}_{i}^{*}(f)\right|^{2}}{\sum_{i=1}^{n_{s}} \hat{X}_{i}(f) \hat{X}_{i}^{*}(f) \sum_{i=1}^{n_{s}} \hat{Y}_{i}(f) \hat{Y}_{i}^{*}(f)}
\end{aligned}
$$

Here, ${ }^{*}$ denotes the complex conjugate and the weighting function is $w(\tau)$.

As a calculated quantity the estimated MSC value is always nonzero. Consequently, nonzero values can appear even if the two series are independent. One needs a threshold value of MSC to decide if two series are related over some frequency range. Practical calculation of the estimated MSC show its statistical nature. Consequently, the statistical properties of the MSC have been studied theoretically by Carter ${ }^{19}$ and using simulation method by Foster and Guinzy ${ }^{21}$ Benignus, ${ }^{22}$ and Miles. ${ }^{7}$ These studies indicate that if the true MSC is zero and the two time series, $x_{n}(t)$ and $y_{n}(t)$ are independent then the probability, $P_{I}$, that the estimated MSC, $\left|\hat{\gamma}_{x y}\right|^{2}$, is in the interval, $0<\left|\hat{\gamma}_{x y}\right|^{2}<E_{I}$ is related to $E_{I}$ by

$$
E_{I}=1-\left(1-P_{I}\right)^{1 /\left(n_{s}-1\right)}
$$

In addition, it can be shown that the expected value of the estimated MSC when the true MSC is zero, $E\left[\left.\left|\hat{\gamma}_{x_{n} y_{n}}\right|^{2}(f)\left|n_{s},\right| \gamma\right|^{2}=0\right]$, is only a function of the number of independent blocks used to average the MSC.

$$
E\left[\left.\left|\hat{\gamma}_{x_{n} y_{n}}\right|^{2}(f)\left|n_{s},\right| \gamma\right|^{2}=0\right]=\frac{1}{n_{s}}
$$

The quantity $\left|\hat{\gamma}_{x_{n} y_{n}}\right|^{2}=E_{I}$ can serve as a threshold in deciding if two series are uncoupled. In addition, it is possible to calculate a confidence interval for $\left|\hat{\gamma}_{x y}\right|^{2}(f)$ for any value of $\left|\gamma_{x y}\right|^{2}(f)$ using the conditional probability equations of Carter ${ }^{19}$ and a method discussed by Wang et al. ${ }^{23,24}$

Unfortunately, the theoretical foundation for the statistical threshold value does not include the possibility that the samples used in estimating the MSC are overlapped. In addition, the use of different weighting functions, $w(\tau)$, is common and might make the statistically derived threshold questionable. These type of questions lead to the use of simulation methods and surrogate methods to determine threshold values.

The method of surrogate data analysis modifies a set of measurements to study its properties ( Faes, ${ }^{25}$ Theiler ${ }^{26}{ }^{\text {Schreiber }}{ }^{27}$ ). The method of surrogate data analysis has been used to determine a MSC threshold by Faes. ${ }^{25}$ According to this method a set of surrogate series mimicking some properties of the original series but being otherwise uncoupled is generated. The threshold for zero coherence is then computed on the distribution of coherence estimates obtained from the surrogate series. For example, one of the procedures 
used by Faes to generate a surrogate series was to randomly permute in temporal order the samples of the original series so that any temporal structure was destroyed in the surrogate generation. This procedure was devised for cardiovascular variability analysis where the coherence between the spontaneous fluctuations of heart period, systolic pressure, and respiration are used to quantify the amount of correlation between these oscillatory components and the reliability of transfer function estimates $\left(\right.$ Faes $\left.^{25}\right)$.

This paper uses a novel measurement technique involving aligned and unaligned coherence functions and a novel data processing methodology to determine a threshold for zero coherence. First the measurement technique will be discussed. Then the data processing methodology will be outlined.

\section{A. Measurement scheme}

This aligned and unaligned coherence function measurement technique is described in great detail by Miles. ${ }^{7}$ The technique works because of time delay bias. Seybert and Hamilton ${ }^{28}$ show that if one uses an average periodogram type calculation procedure to calculate MSC the time delay bias is

$$
|\hat{\gamma}|_{x y}^{2}=\frac{\left|G_{x y}\right|^{2}}{G_{x x} G_{y y}}=\left(1-\frac{|D|}{T_{d}}\right)^{2}|\gamma|_{x y}^{2}
$$

where $D$ is the delay time.

This relationship has been used to explain time delay bias by Halvorsen and Bendat, ${ }^{29}$ Seybert and Hamilton, ${ }^{28}$ Bendat and Piersol ${ }^{18}$ in chapter 11.2 (page 271) and Carter. ${ }^{19,30}$

The method of aligned and unaligned coherence is based on the following two characteristics of the average periodogram process when it is used to calculate the MSC :

- When the time delay, $D$, exceeds the sample record length,$T_{d}$, the coherence of the random process, $\hat{\gamma}_{x y}^{2}(f)$, is the coherence of two independent random signals, $\hat{\gamma}_{x_{n} y_{n}}^{2}(f)$.

- If the signals contain tones using a time delay, $D$, greater than the sample record length,$T_{d}$, does not change the coherence of the tones.

\section{B. Data processing scheme}

The unaligned coherence is identical to the coherence that would be measured if the signals from the two Kulites were independent. The unaligned coherence is used as a reference threshold for identifying the independence of two time histories. The coherence is studied without the frequency dimension using only the coherence magnitude. The magnitude of the coherence is a variable which has a distribution that expresses the difference between the aligned coherence and the unaligned reference coherence. In order to magnify the difference between the aligned and unaligned coherence a variable transformation is used to make the distributions more symmetric and normal. Various two parameter statistical hypothesis testing procedures using conventional statistical methods ${ }^{1-3}$ and a robust statistical method developed by Yuen ${ }^{4-6}$ are applied to form a parameter that indicates sensor degradation, total sensor failure, or a change in the signal. The results are obtained since multivariate normal distributions play a pivotal role in the theory of multivariate statistical analysis which is used such diverse fields as control theory, stochastic systems, statistical signal analysis and multiple time series. ${ }^{31-34}$

Experimental data from Kulite pressure transducers mounted in a Pratt \& Whitney PW4098 combustor is used to demonstrate the proposed method. This experiment is discussed first. Next the treatment of the Kulite signals is discussed. Then the data transformation and results of the statistical hypothesis testing procedures are discussed.

\section{Experiment}

To demonstrate the usefulness of the proposed aligned and unaligned coherence method, Kulite pressure measurements made in a Pratt \& Whitney PW4098 combustor will be used. The measurements were made in a study of aircraft engine core noise conducted as part of the NASA Engine Validation of Noise Reduction Concepts (EVNRC) Program. One Kulite was at 127 degrees and the other was at 337 degrees. Kulite angles are measured clockwise from top dead center viewed from the rear or exhaust. The spectral estimate parameters are shown in table table 1 on the following page The signal processing algorithms used were 
written in Fortran based on subprogram modules developed by Stearns and David ${ }^{20}$ and were modified for this project so that the time series could be translated. In the calculations the segments were overlapped by 50 percent.

The test stand is shown in Fig. 1 on page 3. The Kulites mounted in the combustor with water cooled jackets are shown in Fig. 2 on the following page.

The three test cases shown herein are for test points with at $1622 \mathrm{rpm}, 1999$ rpm, and $2600 \mathrm{rpm}$ (N1 CORR).

\section{A. Combustor Kulites}

Selected plots of Kulite auto spectra and cross spectra are shown in Fig. 3 on page 9. Corresponding aligned and unaligned coherence functions are shown in Fig. 4 on page 11.

Results of modal model analysis are discussed in Appendix B. Again, note that approaches to find a single number that describes the use of the aligned and unaligned coherence functions and statistical theory to test for sensor degradation, total sensor failure or changes in the signal will be shown for a range of engine speeds. However, only data for three cases are presented $1622 \mathrm{rpm}, 1999 \mathrm{rpm}$, and 2600 $\operatorname{rpm}(\mathrm{N} 1 \mathrm{CORR})$.

Given measurements from two sensors in a combustor to examine, we say a sensor is providing no information if the signals are uncorrelated with each other. In addition we suspect a sensor is providing an incorrect signal if the correlation changes abruptly in some irregular fashion. This paper uses the coherence function to determine if the signals from two sensors become uncorrelated or change in some strange fashion. The procedure used compares the normal measured coherence, $\hat{\gamma}_{r_{k} r_{\ell}}^{2}(f)$, called the aligned coherence with one calculated by time delaying one signal by an amount $D$ greater than the sample interval $T_{d}$. The value of $D$ is chosen so that the two signals are not in the same sample interval, $T_{d}$ and appear to the processing procedure to be uncorrelated. In the paper a value of $D$ approximately 1.5 times the sample interval is used. Thus to calculate the unaligned coherence we have

$$
\begin{aligned}
r_{k}(t) & =s_{1}(t)+n_{k}(t) \\
r_{\ell}(t-D) & =s_{2}(t-D)+n_{\ell}(t-D)
\end{aligned}
$$

The same signal processing algorithms are used for the unaligned time series. However, since the two series are now uncorrelated the ensemble average of the cross-spectrum is that of an uncorrelated process.

The measured unaligned coherence, $\hat{\gamma}_{r_{k} r_{\ell}}^{2}(f, D)$ is not zero. For example, if tones are present in the time signal they will be in all ensembles and appear in the unaligned and aligned coherence. In addition to aiding the identification of persistent tones, the unaligned coherence provides a reference coherence. Small values of the aligned coherence greater than the unaligned reference coherence can be easily identified as significant since one knows what the uncorrelated coherence looks like.

However, the major support it provides is in determining if a sensor is providing a useful signal. If the aligned and unaligned coherence are similar than the two sensors are uncorrelated and one sensor may have failed. For the experiment discussed herein, an examination of the two auto-spectra can be used to identify the sensor failure.

The creation of the unaligned coherence has the same advantage as using a placebo in a medical study. In developing a drug or medical procedure due to factors such as the natural biological variability between individual patients and the placebo effect (i.e. a response due to therapy rather than the type of therapy) one cannot usually conclude that some therapy was beneficial on the basis of experience. Examples of 


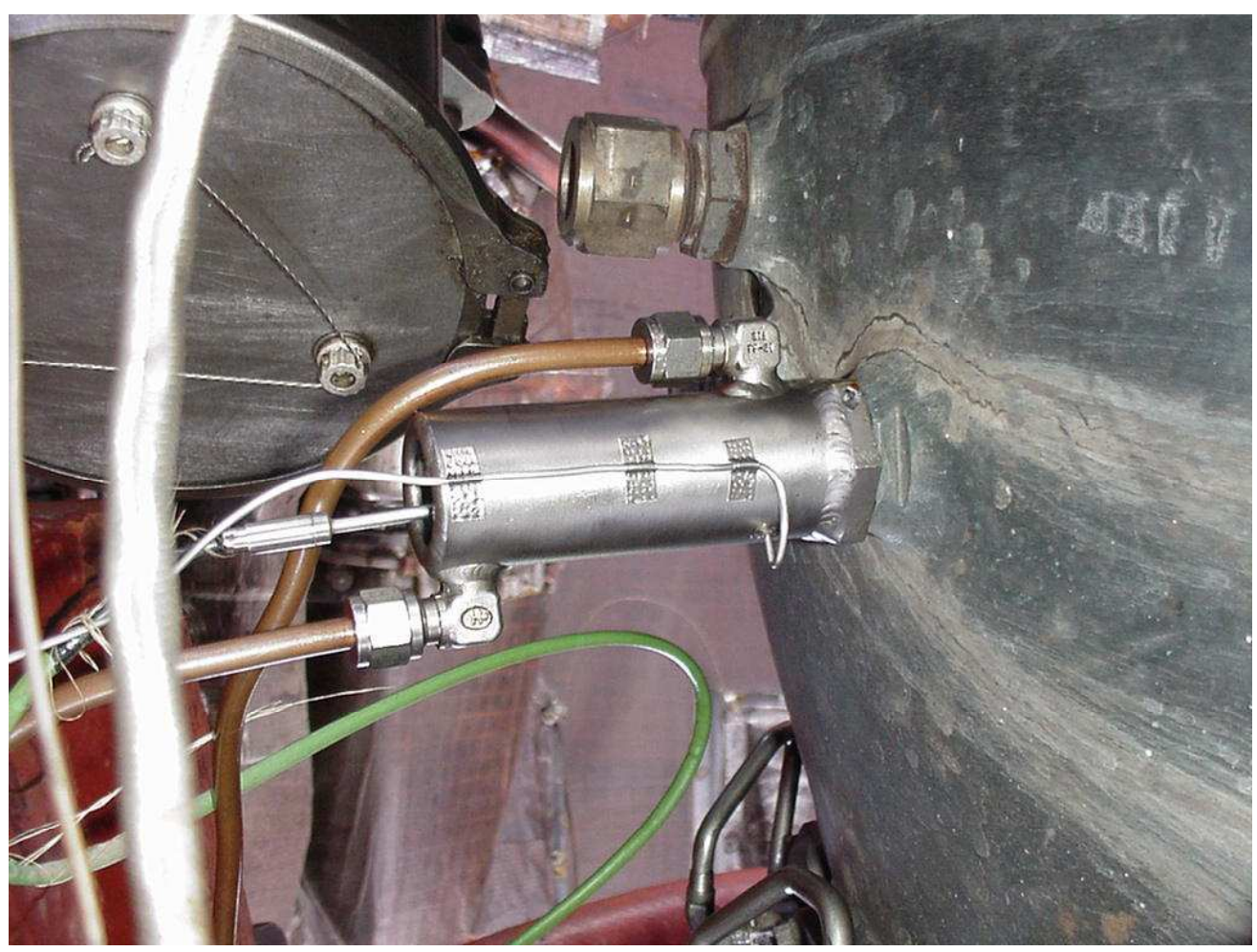

Figure 2. Kulite hardware mounted on PW4098 turbofan engine at Pratt \& Whitney test stand C11, West Palm Beach Florida for EVNRC Phase 2 tests.

placebos are an injection of saline, a sugar pill, and surgically opening and closing without doing a surgical procedure. Creating the unaligned coherence from the same signals takes into account the variability due to the operating condition and provides a set of data one may compare with the aligned coherence to determine any difference.

The data processing methodology will be discussed next and the statistical approaches used will be presented.

\section{Transforming Data}

A number of schemes will be developed which produce a single number that provides knowledge about the degree of degradation from normal operating performance and the total failure of a pair of Kulite pressure transducers mounted in a combustor. This will show that having the unaligned and aligned coherence is a very robust procedure that produces information that can used by a variety of methods.

The aligned coherence is a positive function due to broad band combustion noise, tones, and random noise. The unaligned coherence function is due to tones and random noise. One expects that at any particular frequency the magnitude of the unaligned coherence will be lower than the magnitude of the aligned coherence.

When a coherence function is due to random noise, the coherence is low and the plot of coherence verses frequency consists of random points. However, the unaligned coherence can have a component due to tones in addition to one due to random noise. One result from the mathematical field of combinatorics is Ramsy's Theorem which states that complete disorder is unlikely. No matter how jumbled and chaotic the arrangement the viewer creates a very highly organized and structured object within it. ${ }^{35}$ Thus looking at a coherence plotted verses frequency due to random noise one sees patterns in the plot just as one can see shapes in the night sky created by randomly arranged stars. The presence of tones in the unaligned coherence make it even easier to see patterns when viewing the coherence as a function of frequency.

In order to study the coherence without the frequency dimension and to include the whole range of coherence values measured in a frequency band just the magnitudes will be considered. The transformed magnitude of the coherence is posited as a dimension which has a distribution that expresses the difference 
between the aligned and unaligned coherence function independent of frequency. In order to magnify the difference between the aligned and unaligned coherence a variable transformation will be used to make the distributions more symmetric and normal. The magnitude after transformation becomes an "evidence" dimension. Larger values along this dimension above some threshold value provide evidence of correlation between two time series. Values below some threshold provide evidence that the two time series are independent Observations of the aligned and unaligned coherence have different distributions of the transformed function of the coherence because the ensemble average process shifts the aligned coherence along the evidence dimension to a higher level relative to the unaligned coherence. The evidence dimension used herein is

$$
\eta=8+3.75 * \log _{10}\left(\hat{\gamma}_{12}^{2}\right)
$$

This scaling is selected to position the center of the unaligned coherence distribution near zero $(\eta=0.0)$ since $\eta=0$ corresponds to $\hat{\gamma}_{12}^{2}=0.007356=10^{-8 / 3.75}$ which is near the mean value of the unaligned coherence.

The statistical treatment is based on the idea that the frequency label is more like an observation label. For each case the experimenter makes $\mathrm{M}$ observations i.e. the magnitude of the coherence and classifies them into a set of qualitative measurement classes. The results are independent of the order the observation are made in. Thus creating this statistical study the frequency associated with a coherence value is ignored. The study focuses on the statistical distribution of magnitudes of coherence values in a class. In order to get some idea of the frequency dependence this is done for five frequency intervals or classes: $[0,809],[0,199],[211,398],[410,610],[621,808] \mathrm{Hz}$. . The maximum number of points in the interval is limited since $\Delta f=11.718 \mathrm{~Hz}$. This is a result of the use of a record length of 20 seconds and a selection of a reasonable number of ensemble averages. The number of points is reduced by neglecting points at the same frequency in the aligned and unaligned coherence which have levels which are closer than some set limit and might be due to tones. In the $800 \mathrm{~Hz}$. interval there are typically sixty points and in the $200 \mathrm{~Hz}$. interval there are typically sixteen points. The number of points seem sufficient to provide guidance as to sensor operation.

\section{Two Parameter Statistical Hypothesis Testing}

Many two parameter statistical hypothesis testing schemes are available. Selection of a scheme is based on knowledge about the statistical properties of the distributions such as if the population variance equals the sample variance. The following functions are calculated using standard statistical procedures based on the Student $t$ test and Normal test ${ }^{1-3}$. The normal test is used if one may assume the distribution is normal and the population size is large. The Student $t$ test is used if the population size is small and the probability curve is symmetric.

They are used herein to compare the transformed aligned coherence magnitude and the transformed unaligned coherence magnitude distributions:

$$
\begin{aligned}
& \Lambda_{1}=\left|\mu_{\text {aligned }}-\mu_{\text {unaligned }}\right|-1.96 \sqrt{\sigma_{\text {aligned }}^{2} / n+\sigma_{\text {unaligned }}^{2} / n} \\
& \Lambda_{2}=\left|\mu_{\text {aligned }}-\mu_{\text {unaligned }}\right|-t_{1-\alpha / 2 ; \nu} \sqrt{\sigma_{\text {aligned }}^{2} / n+\sigma_{\text {unaligned }}^{2} / n}
\end{aligned}
$$

We call $\Lambda$ a confidence test parameter. The $\Lambda_{1}$ test is based on the normal distribution. The $\Lambda_{2}$ test is based on Student's t distribution. The above formula applies if the number of samples $n$ in the aligned and unaligned samples are equal. A more general t test is available if the two samples are not the same size. ${ }^{3}$ The quantity $\mu$ is the mean or expected value of the appropriate aligned or unaligned coherence functions over the desired frequency range. The quantity $\sigma^{2}$ is the variance, which is the expected squared deviation from the mean of the appropriate aligned or unaligned coherence functions over the desired frequency range.

Plots of these functions are shown in Fig. 5 on page 12. The curves were created using values of the parameters obtained by arithmetic averaging.

When the function is positive the aligned coherence mean is not near the unaligned coherence and the sensor has not failed. However, in addition, the function provides information on signal changes and sensor degradation. Numerical values are given in table 1 and 2. 

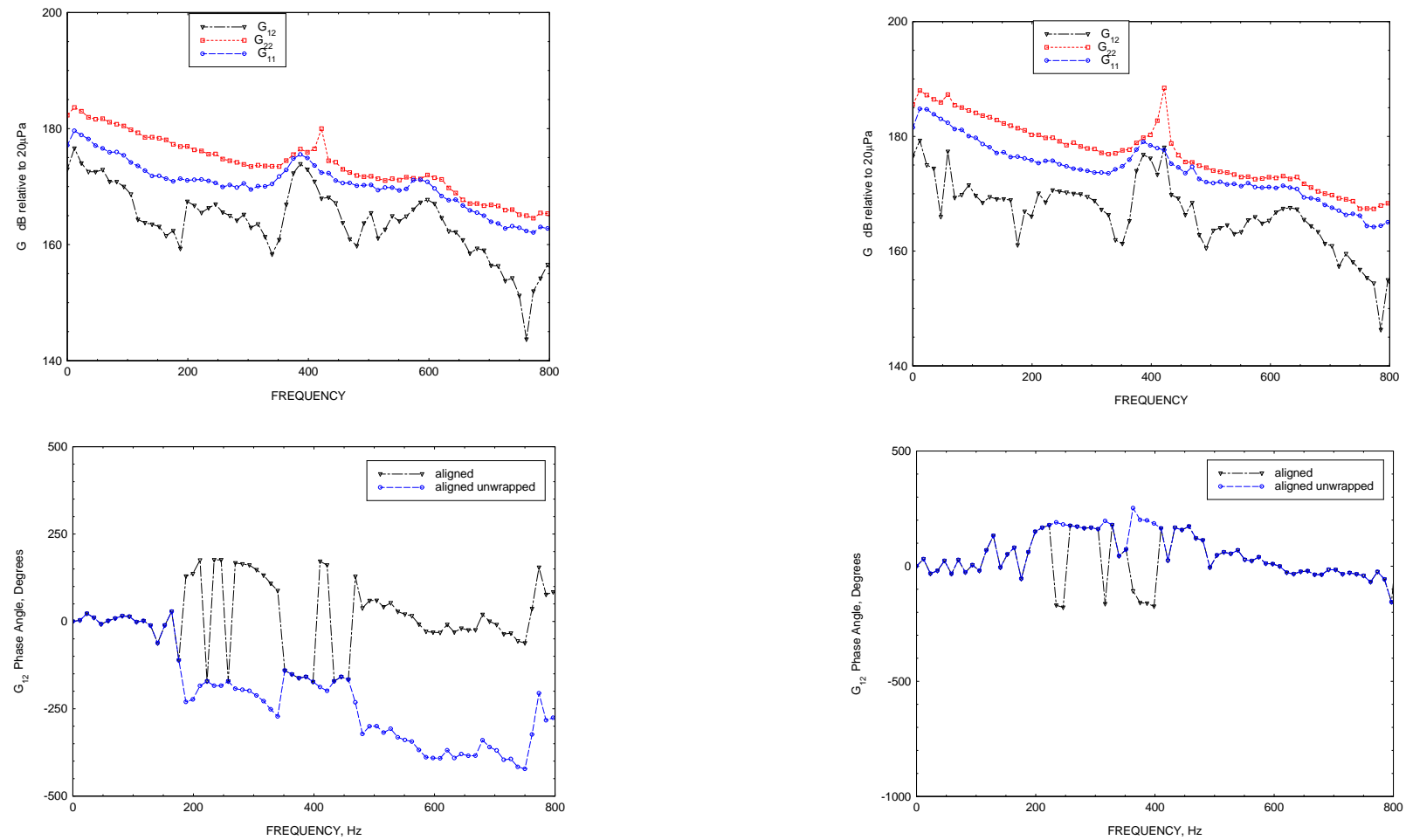

(a) 1622. rpm (N1 CORR)

(b) 1999. rpm (N1 CORR)
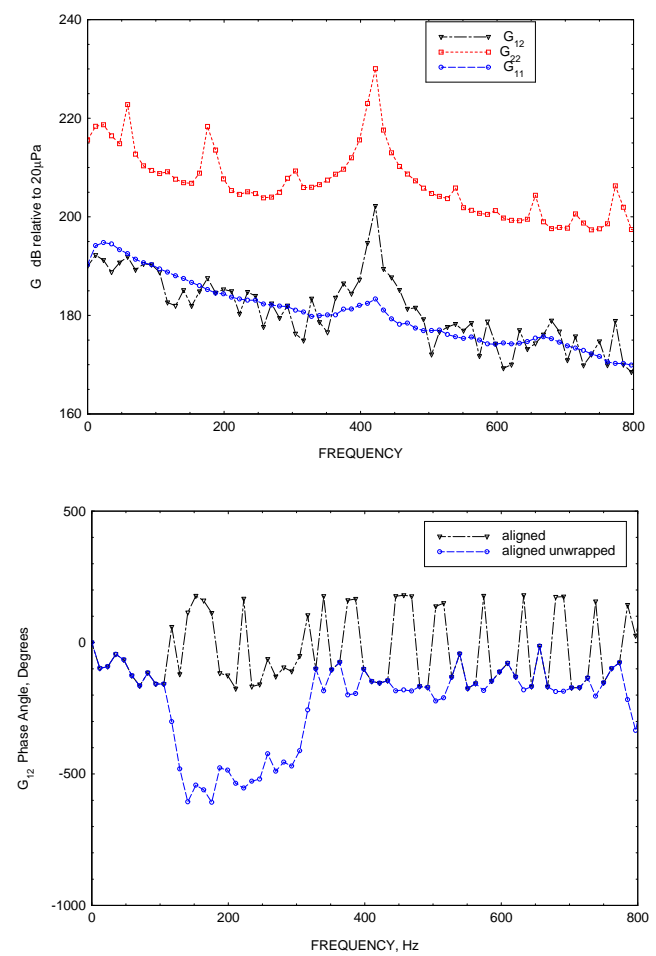

(c) 2600. rpm (N1 CORR)

Figure 3. Auto-spectrum magnitude for Kulite (1) at 127 degrees and Kulite (2) at 337 degrees and crossspectrum magnitude and phase between Kulite (1) and Kulite (2). 
The third method uses a robust statistical method developed by Yuen ${ }^{4-6}$ called the Yuen-Welch test This test examines the hypothesis that two independent groups have equal trimmed means and enables the computation of a confidence interval. This test is used if the population size is small and has outliers and the probability curve is nonnormal.

The Yuen-Welch test states the $1-\alpha$ confidence interval for $\mu_{1 t}-\mu_{2 t}$ is

$$
\Lambda_{3}=\left(\bar{X}_{t 1}(g)-\bar{X}_{t 2}(g)\right) \pm t_{Y u e n} \sqrt{d_{1}+d_{2}}
$$

where $\bar{X}_{t 1}$ is the sample trimmed mean of aligned coherence values, $\bar{X}_{t 2}$ is the sample trimmed mean of unaligned coherence values, $d_{1}$ is Yuen squared standard error of the aligned coherence values, $d_{2}$ is Yuen squared standard error of the unaligned coherence values,and $t_{Y \text { uen }}$ is the $1-\alpha / 2$ quantile of Student's $\mathrm{t}$ distribution with $\hat{\nu}_{Y \text { uen }}$ degrees of freedom.

When $\Lambda_{3}$ is positive the hypothesis that the trimmed means of the aligned and unaligned coherence are equal is rejected.

The Yuen procedure confidence interval is shown in figure 5 on page 12 and is marked as high $\left(\Lambda_{3}^{+}\right)$and low $\left(\Lambda_{3}^{-}\right)$. The Yuen procedure lower confidence interval value $\left(\Lambda_{3}^{-}\right)$is in good agreement with the values of $\Lambda_{1}$ and $\Lambda_{2}$ which are calculated using standard statistical procedures using the Student t test and Normal test.

\section{Discussion}

Selected plots of auto spectra and cross spectra (figure 3 on the preceding page) and aligned and unaligned coherence (figure 4 on the next page) have been presented so that the sensor degradation, total sensor failure, and changes in the signal unrelated to the sensor operation as observed in the plots can be compared to the single parameter validity measurement discussed in the last section. These auto spectra and cross spectra plots when compared to the decision criteria proposed provide insight into the value of a particular approach. However, one might decide that using the approach presented in this section based on aligned and unaligned cross spectra provides sufficient information. Statistical theory adds no new information to the plots of the test cases. The statistical theory approach discussed does simplify and compress the results so that one figure can provide a test for sensor degradation, total sensor failure or changes in the signal.

The results of Yuen's confidence method and the standard statistical methods are shown in figure 5 on page 12. Results are shown for aligned and unaligned coherence function distributions of magnitude based on five frequency intervals : [0,809] Hz., [0,199] Hz., [211,398] Hz., [410,610] Hz., and [621,808] Hz. . All the procedures produce similar results. The fact that the robust statistical procedure of Yuen which compares trimmed means agrees with standard statistical procedures which compare mean values of aligned and unaligned coherence magnitudes shows that using the standard statistical procedures is feasible.

The degradation of performance of the Kulite pair during the test is clearly shown in figure 5 on page 12 The aligned and unaligned coherence are nearly the same at $2600 \mathrm{rpm}$ (N1 CORR) where the confidence interval start to include zero and the values of $\Lambda_{1}$ and $\Lambda_{2}$ go negative. Note that after failure the values go up. This is due to coherence between the signals from failed Kulite 2 and Kulite 1. A look at the Auto spectrum of Kulite 2 at $2600 \mathrm{rpm}$ (N1 CORR) clearly show it has failed.

The plane wave mode as identified as being in the 0 to $200 \mathrm{~Hz}$ frequency range Appendix B dominates at low engine speed (Appendix B). However, the most interesting point is that the plane wave combustion noise vanishes at higher $\mathrm{rpm}(\mathrm{N} 1 \mathrm{CORR})$ values while the noise in other modes remains. This is clearly shown by comparing the confidence interval plots in figure 5 on page 12 . The curves in Fig. $5 \mathrm{~b}$ covering the $[0,199] \mathrm{Hz}$. interval are below zero at $2000 \mathrm{rpm}$ while the curves in Fig. 5c remain above zero until 2400 rpm.

The proposed tests go negative above $2500 \mathrm{rpm}$ ( N1 CORR) as shown in Fig 5a when Kulite 2 fails as shown in figure 3 on the page before. Note however that the failure is not sudden but starts at $2250 \mathrm{rpm}$ ( N1 CORR).

\section{Conclusions}

A novel diagnostic procedure for sensor evaluation in a harsh environment based on aligned and unaligned coherence functions was compared with a method based on examination of auto-spectra. The new method is more effective in that it clearly indicates the signals are uncorrelated if a sensor fails. In addition, it does 


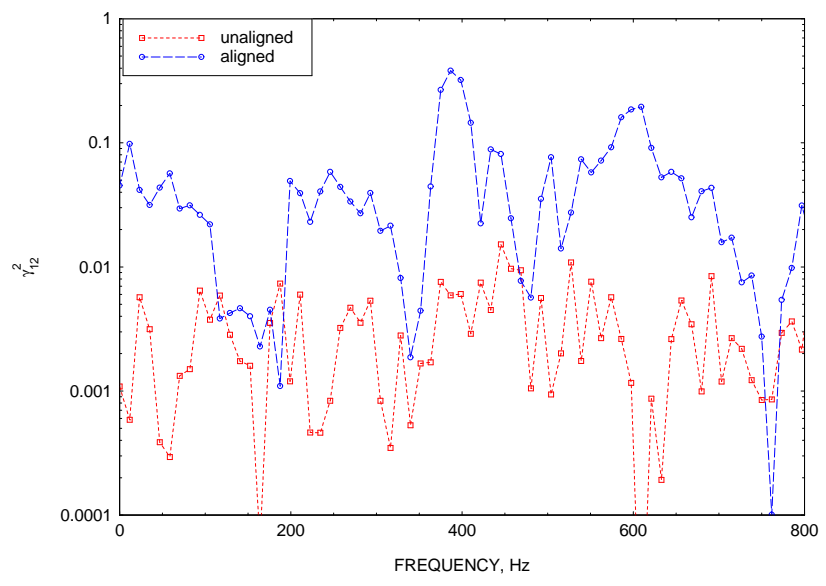

(a) 1622. rpm (N1 CORR)

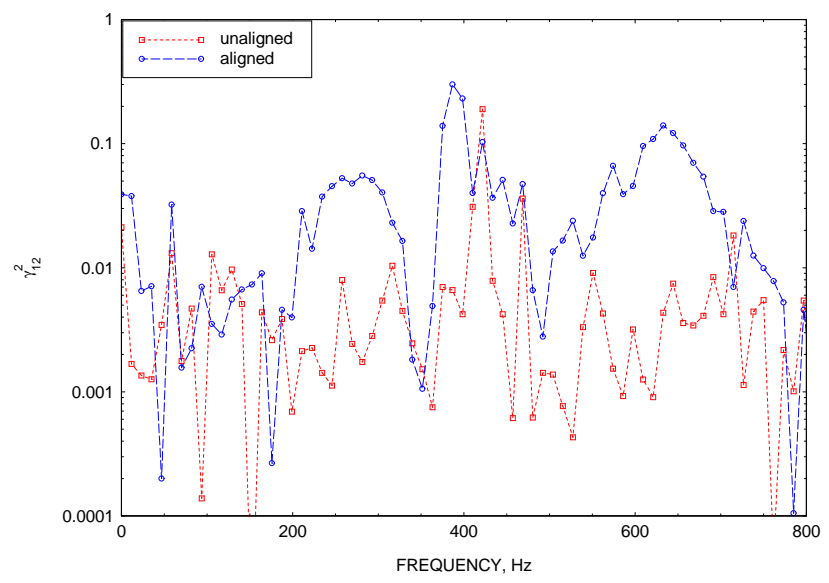

(b) 1999. rpm (N1 CORR)

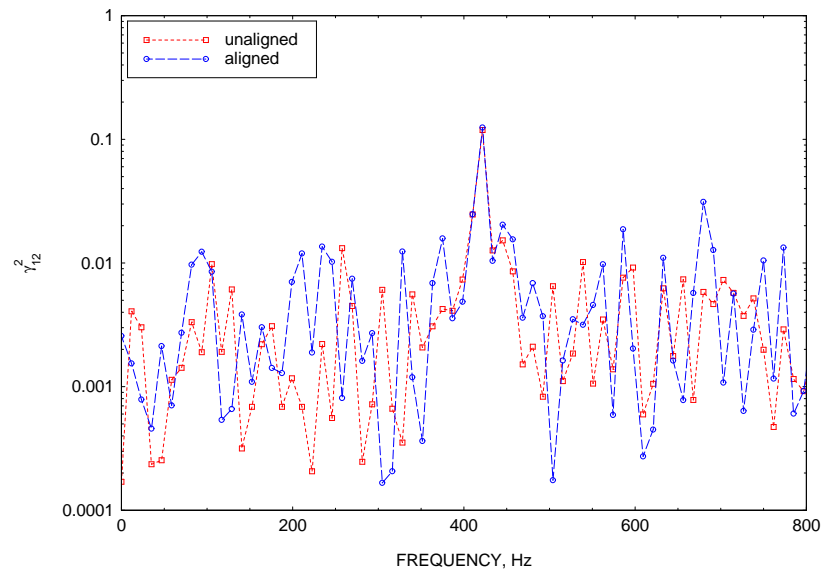

(c) 2600. rpm (N1 CORR)

Figure 4. Comparison of aligned and unaligned coherence between combustor Kulite (1) at 127 degrees and combustor Kulite (2) at 337 degrees. 


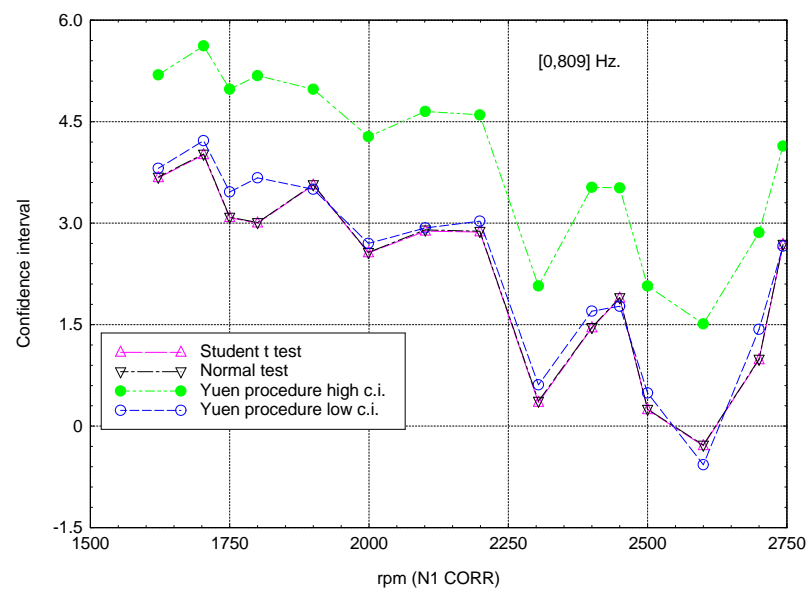

(a) $(0,809) \mathrm{Hz}$.

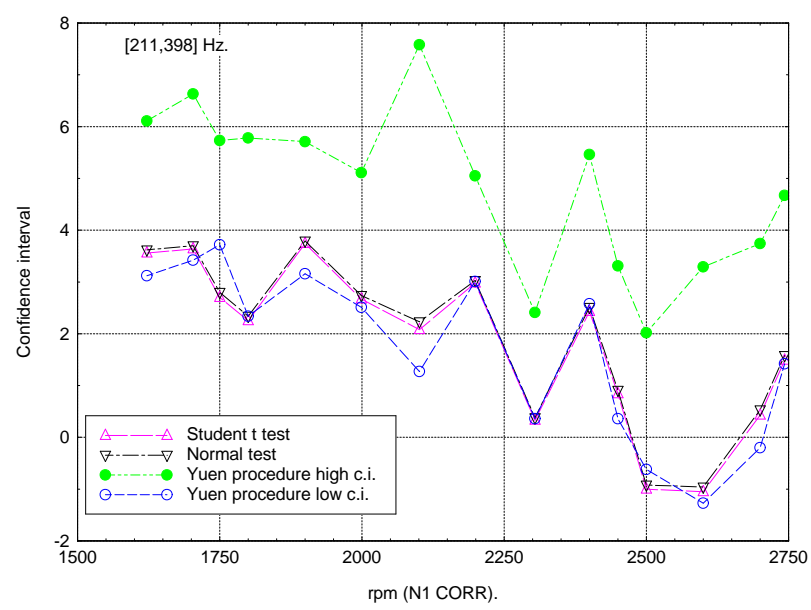

(c) $(211,398) \mathrm{Hz}$.

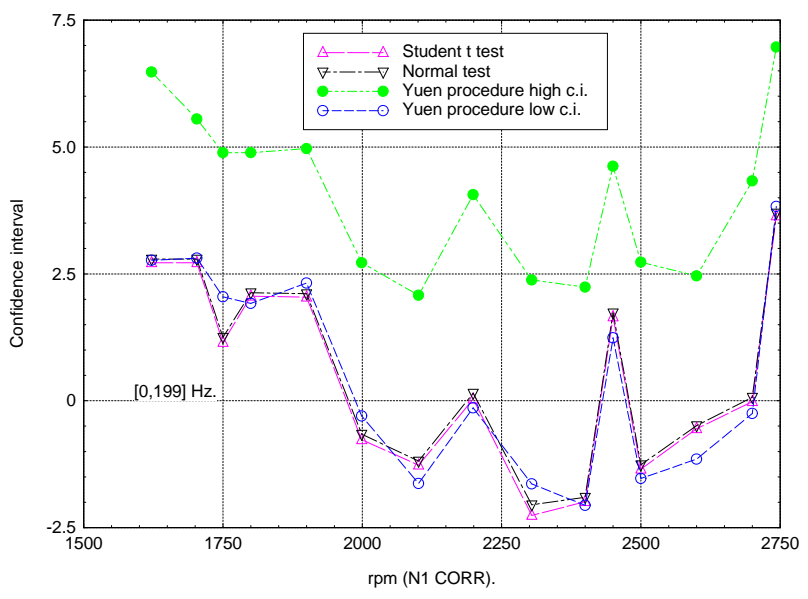

(b) $(0,199) \mathrm{Hz}$.

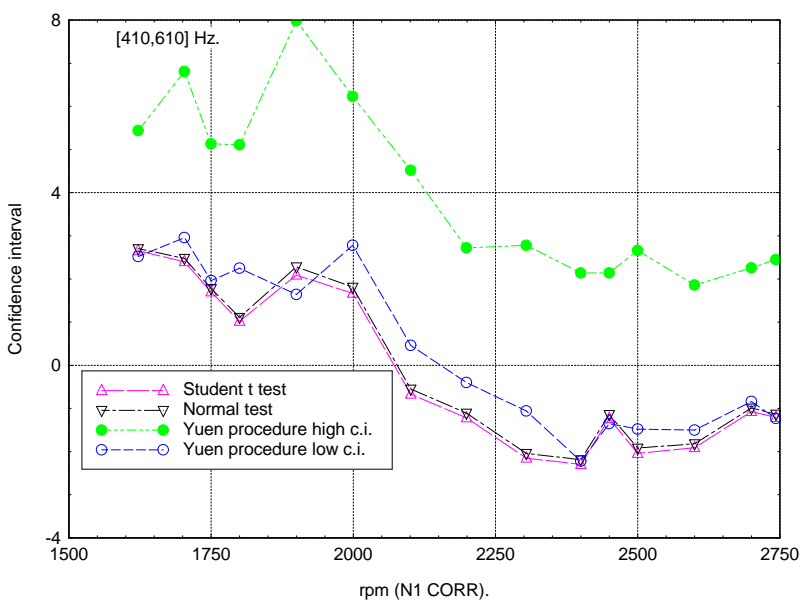

(d) $(410,610) \mathrm{Hz}$.

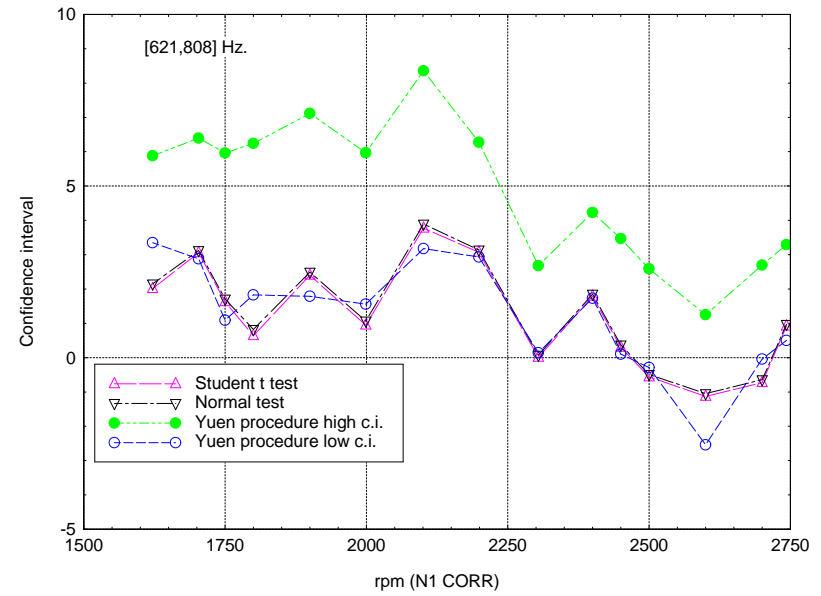

(e) $(621,808) \mathrm{Hz}$.

Figure 5. Confidence interval. 
this a priori .i.e without a prior model of the sensor. Furthermore, it enables one to have confidence that low values of coherence are significant.Examination of the coherence does not identify the failed unit. A failed unit can be identified using the Kulite auto-spectra. Examination of experimental data from Kulite pressure transducers mounted in a Pratt \& Whitney PW4098 combustor by spectrum analysis of aligned and unaligned time histories has verified the effectiveness of the proposed method.

Using a novel data processing methodology, statistical tests based on standard techniques and a robust statistical procedure by Yuen that uses trimmed means were examined to develop a single parameter measure of the validity of signals from the Kulite pair. All the procedures produce good results which demonstrates how robust the technique is.

While the technique was developed to validate turbofan instrumentation, it might also be useful in medical fields where the coherence function is used to assess the significance of relationships of fluctuations in oscillatory components like heart period, systolic pressure, and respiration. 


\section{A. Auto Spectra and Coherence}

Figure 3 shows the magnitude of the auto-spectra and the cross-spectra and the wrapped and unwrapped phase angle of the cross-spectra for three engine speeds.

At the $1622 \mathrm{rpm}$ (N1 CORR)and $1999 \mathrm{rpm}$ (N1 CORR) operating conditions the cross-spectra plots resemble those measured by Karchmer in a study of core noise from a YF102 turbofan engine Ref. ${ }^{36,37}$ Karchmer showed that individual features of the combustion noise spectrum can be uniquely related to a specific propagation mode. It was found that the pressure field in the PW4098 engine combustor can be reconstructed in a similar manner that the pressure field in the YF102 combustor was reconstructed.

The model used is based on the assumption that there are distinctive frequency bands over which the individual modes, including the plane wave can be treated as existing. Furthermore, for all modes but the plane wave mode the modes are assumed to overlap such that when mode $m$ and mode $m-1$ are present mode $m-2$ is not present.

Next we mention some of the results and illustrate them with a few examples. For the engine speed, 1622 rpm (N1 CORR) case auto-spectra and cross-spectra are shown in Figure 3a and aligned and unaligned coherence functions are shown Figure 4a. Using the modal model results we see

1. the plane wave mode $\mathrm{A}(0,0)$ below $187.5 \mathrm{~Hz}$.

2. the circumferential mode, A $(1,0)$, between $187.5 \mathrm{~Hz}$ and $500 \mathrm{~Hz}$.

3. the circumferential mode, A $(2,0)$, between $500 \mathrm{~Hz}$ and $800 \mathrm{~Hz}$.

4. the circumferential mode, A $(3,0)$, above $800 \mathrm{~Hz}$.

At higher engine speeds similar model patterns appears.

Examining the coherence plots in view of the results from the modal model suggest that in the 0 to 200 $\mathrm{Hz}$ frequency band, the plane wave mode is very strong at $1622 \mathrm{rpm}, 1703 \mathrm{rpm}, 1750 \mathrm{rpm}$, and $1800 \mathrm{rpm}$. However, the plane wave mode starts to vanish at $1900 \mathrm{rpm}$ and is gone at $1999 \mathrm{rpm}$. The presence of acoustic duct modes at higher frequencies as shown by the plots clearly indicates the sensors have not failed and that the noise source in the 0 to $200 \mathrm{~Hz}$ frequency range has changed. This is effect illustrated by Figure 3b and Figure 4b where results for the 1999 rpm case are shown.

The magnitude of the auto-spectra for Kulite (1) and (2) are similar until $2450 \mathrm{rpm}$. At that point Kulite (2) fails. At this engine speed the unaligned and aligned coherence become similar. In addition, the autospectrum $G_{22}$ does not resemble $G_{11}$. For the previous speed the two are similar. Above $2450 \mathrm{rpm}$ the $G_{22}$ spectrum is at least $20 \mathrm{~dB}$ higher than $G_{11}$. This behavior is illustrated in Figure 3c where auto-spectra and cross-spectra results for the $2600 \mathrm{rpm}$ case are plotted.

At each engine speed, the aligned coherence clearly shows the plane wave and circumferential propagation mode shapes. The unaligned coherence serves as a reference. It indicates, what the coherence would be if the Kulites were uncorrelated and the location of tones. The aligned and unaligned coherence are different until $2450 \mathrm{rpm}$. Figure 4 illustrates this behavior for the three engine speed cases discussed herein. A tone at $421.875 \mathrm{~Hz}$ is especially noticeable in many of the Figure 4 plots. At higher engine speeds above 2450 rpm the aligned and unaligned coherence functions are similar indicating the two sensors are uncorrelated and one sensor may have failed. To identify the failed unit as Kulite (2), one must examine the auto-spectra. Fig 3c show a typical case. 


\section{References}

${ }^{1}$ Isaac N. Gibra. Probability and Statistical Inference for Scientists and Engineers. Prencice-Hall, Inc., 1973. ISBN 0-13-711622-5.

${ }^{2}$ George W. Snedecor and William G. Cochran. Statistical Methods, Eighth Edition. Iowa State Press, 1989. ISBN 0-8138-1561-4.

${ }^{3}$ Stanton A. Glantz. Primer of Biostatistics:Third Edition. McGraw-Hill, 1992. ISBN 0-07-023511-2.

${ }^{4} \mathrm{~K}$. K. Yuen. The two sample trimmed t for unequal population variances. Biometrika, 61 :165-170, 1974.

${ }^{5}$ R. R. Wilcox. Some results on the tukey-mclaughlin and yuen methods for trimmed means when distributions are skewed. Biometrical Journal, 36 :259-306, 1994. Robust: wilcox1997 page 110.

${ }^{6}$ Rand R. Wilcox. Introduction to Robust Estimation and Hypothesis Testing. Academic Press, 1997.

${ }^{7}$ Jeffrey Hilton Miles. Aligned and unaligned coherence: A new diagnostic tool. Technical Report AIAA-2006-0010, AIAA, 2006. Presented at the 44th AIAA Aerospace Science Meeting, 9-12 Jan 2006 Reno Hilton Reno, Nevada.

${ }^{8}$ T.-H. Guo and J. Musgrave. Neural network based sensor validation for reusable rocket engines. In Proceedings of the American Control Conference, 1995, volume Volume: 2, 21-23 June 1995, pages $1367-1372$ vol.2, 1995.

${ }^{9}$ P.H. Ibarguengoytia, L.E. Sucar, and S. Vadera. Real time intelligent sensor validation. IEEE Transactions on Power Systems, 16 Issue 4:770 -775, Nov. 2001.

${ }^{10}$ S.J. Wellington, J.K. Atkinson, and R.P Sion. Sensor validation and fusion using the nadaraya-watson statistical estimator. In Proceedings of the Fifth International Conference on Information Fusion, Volume: 1, 8-11 July 2002, pages 321 -326 vol.1, 2002 .

${ }^{11}$ S.K. Yung. Local validation of sensor signals. In IEE Colloquium on Fault Diagnosis and Control System Reconfiguration, pages $7 / 1-7 / 8,1993$.

${ }^{12}$ D. M. Himmelblau and M. Bhalodia. On-line sensor validation of single sensors using artificial neural networks. In Proceedings of the American Control Conference, 1995., Volume: 1, pages 766-770, 1995.

${ }^{13}$ J. Ma, J.Q. Zhang, and Y. Yan. Wavelet transform based sensor validation. IEE Colloquium on Intelligent and SelfValidating Sensors (Ref. No. 1999/160), 1999/160:10/1 -10/4, June 1999.

${ }^{14}$ Diego Del Gobbo, Marcello Napolitano, Parviz Famouri, and Mario Innocenti. Experimental application of extended kaman filtering for sensor validation. IEEE Transactions on control systems technology, 9 No.2:376-380, March 2002.

${ }^{15}$ J.E. Amadi-Echendu and Hengjun Zhu. Detecting changes in the condition of process instruments. IEEE Transactions on instrumentation and measurements, 43 No. 2:1994, April 1994.

${ }^{16}$ Julius S. Bendat and Allan G. Piersol. Measurement and Analysis of Random Data. John Wiley \&Sons, 1966.

${ }^{17}$ Julius S. Bendat and Allan G. Piersol. Random Data: Analysis and Measurement Procedures. John Wiley \&Sons, 1971.

18 Julius S. Bendat and Allan G. Piersol. Engineering Applications of Correlation and Spectral Analysis. John Wiley \&Sons, 1980.

${ }^{19}$ G. Clifford Carter. Coherence and time dealy estimation. Proceedings of the IEEE, 75 No. 2:236-255, February 1987.

${ }^{20}$ Samuel D. Stearns and Ruth A. David. Signal Processing Algorithms Using Fortran and C. Prentice-Hall, Inc., 1993.

${ }^{21}$ M. R. Foster and N. J. Guinzy. The coefficient of coherence: Its estimation and use in geophyiscal dagta processing. Geophysics, 32 No. 4:602-616, August 1967.

${ }^{22} \mathrm{~V}$. A. Benignus. Estimation of the coherence spectrum and its confidence interval using the fast fourier transform. IEEE Trans. Audio Electroacoustics, AU-17 No. 2:145-150, June 1969.

${ }^{23}$ Shou-Yan Wang, Xuguang Liu, John Yianni, R. Christopher Miall, Tipu Z. Aziz, and John F. Stein. Optimising coherence estimation to assess the functional correlation of tremor-related activity between the subthalamic nucleus and the forearm muscles. Journal of Neurosciece Methods, 136 No.:197-205, 2004.

${ }^{24}$ Shou Yan Wang and MengXing Tang. Exact confidence inverval for magnitude-squared coherence estimates. IEEE Signal Processing Letters, 11 No. 3:326-329, March 2004.

${ }^{25}$ Luca Faes, Gian Domenico Pinna, Alberto Porta, Roberto Maestri, and Giandomenico Nollo. Surrogate data analysis for assessing the significance of the coherence function. IEEE Transactions on Biomedical Engineering, 51 No. 7:1156-1166, July 2004.

${ }^{26}$ James Theiler, Stephen Eubank, Andre Longtin, Bryan Galriian, and J. Doyne Farmer. Testing for nonlinearity in time series: the method of surrogate data. Physica D, $\mathbf{5 8}$ No.:77-94, 1992.

${ }^{27}$ Thomas Schreiber and Andreas Schmitz. Surrogate time series. Physica D, 142 No.:346-382, 2000.

${ }^{28}$ A. F. Seybert and J. F. Hamilton. Time delay bias errors in estimating frequency response and coherence funcions. Journal of Sound and Vibration, 60 No. 1:1-9, 1978.

${ }^{29}$ William G. Halvorsen and Julius S Bendat. Noise source identification using coherent output power spectra. Sound and Vibration, 9No.:15-24, 1975.

${ }^{30}$ G. C. Carter. Bias in magnitude-squared coherence estimation due to misalignment. IEEE Trans. ASSP, 28 No. 1:97-99, February 1980 .

${ }^{31}$ N. R. Goodman. On the joint estimation of the spectra, cospectrum, and quadrature spectrum of a two-dimensional statioary gaussian process. Technical Report Scientific paper 10, Engineering Statistics Laboratory of New York University, 1957. AD-134919.

${ }^{32}$ T. W. Anderson. An Introduction to Multivariate Statistical Analysis. John Wiley, New York, 1958. ISBN 0-471-02640-1.

${ }^{33}$ David R. Brillinger. Time Series Data Analysis and Theory -Expanded Edition. Holden-Day, 1981. ISBN:0-8162-1150-7.

${ }^{34}$ A.K. Gupta and D.K. Nagar. Matrix Variate Distributions. Chapman \& Hall/CRC, 2000. ISBN 1-58488-046-5.

${ }^{35}$ Bruce Schechter. My Brain is Open - The Mathematical Journeys of Paul Erdos. Dimon\&Schujster, Inc., 2000.

${ }^{36}$ A. M. Karchmer. Acoustic modal analysis of a full scale annular combustor. Technical Report AIAA Paper 83-0760, NASA, 1983. NASA TM-83334. 
${ }^{37}$ J. Robert Mahan and Allen Karchmer. Combustion and core noise. In Harvey H. Hubbard, editor, Aeroacoustics of Flight Vehicle Theory and Practice, chapter 9, pages 483-517. NASA Reference Publication 1258, Vol. 1 WRDC Technical Report 90-3052, August 1991. 
Table 2. Normal distribution test based scheme.

$\Lambda_{1}=\left|\mu_{s}-\mu_{n}\right|-Z_{1-\alpha / 2} \sqrt{\sigma_{s}^{2} / n+\sigma_{n}^{2} / n}$

95\% confidence level $\alpha=0.05$

\begin{tabular}{|l|r|r|r|r|r|r|}
\hline rpm (N1 CORR) & File & {$[0,809] \mathrm{Hz}$.} & {$[0,199] \mathrm{Hz}$.} & {$[211,398] \mathrm{Hz}$.} & {$[410,610] \mathrm{Hz}$.} & {$[621,808] \mathrm{Hz}$.} \\
\hline 1622 & 1756 & 3.68 & 2.79 & 3.62 & 2.70 & 2.15 \\
\hline 1703 & 1757 & 4.02 & 2.79 & 3.70 & 2.48 & 3.12 \\
\hline 1750 & 1758 & 3.09 & 1.25 & 2.80 & 1.78 & 1.71 \\
\hline 1800 & 1759 & 3.01 & 2.13 & 2.34 & 1.11 & .82 \\
\hline 1900 & 1760 & 3.57 & 2.11 & 3.79 & 2.28 & 2.49 \\
\hline 1999 & 1761 & 2.57 & -.66 & 2.74 & 1.81 & 1.07 \\
\hline 2101 & 1762 & 2.90 & -1.19 & 2.23 & -.55 & 3.89 \\
\hline 2199 & 1763 & 2.88 & .15 & 3.03 & -1.11 & 3.14 \\
\hline 2304 & 1764 & .37 & -2.05 & .38 & -2.04 & .07 \\
\hline 2400 & 1765 & 1.46 & -1.90 & 2.51 & -2.19 & 1.85 \\
\hline 2450 & 1766 & 1.90 & 1.73 & .91 & -1.14 & .37 \\
\hline 2500 & 1767 & .25 & -1.26 & -.92 & -1.92 & -.49 \\
\hline 2600 & 1768 & -.28 & -.49 & -.96 & -1.82 & -1.05 \\
\hline 2700 & 1769 & .99 & .07 & .53 & -.99 & -.64 \\
\hline 2743 & 1770 & 2.69 & 3.70 & 1.58 & -1.13 & .97 \\
\hline
\end{tabular}

Table 3. Student $\mathrm{t}$ distribution test based scheme.

$\Lambda_{2}=\left|\mu_{s}-\mu_{n}\right|-t_{1-\alpha / 2 ; \nu} \sqrt{\sigma_{s}^{2} / n+\sigma_{n}^{2} / n}$

95\% confidence level $\alpha=0.05$

\begin{tabular}{|l|r|r|r|r|r|r|}
\hline rpm(N1 CORR) & File & {$[0,809] \mathrm{Hz}$.} & {$[0,199] \mathrm{Hz}$} & {$[211,398] \mathrm{Hz}$.} & {$[410,610] \mathrm{Hz}$.} & {$[621,808] \mathrm{Hz}$.} \\
\hline 1622 & 1756 & 3.67 & 2.72 & 3.56 & 2.65 & 2.01 \\
\hline 1703 & 1757 & 4.01 & 2.72 & 3.64 & 2.40 & 3.06 \\
\hline 1750 & 1758 & 3.08 & 1.15 & 2.70 & 1.70 & 1.63 \\
\hline 1800 & 1759 & 3.00 & 2.06 & 2.25 & 1.02 & .64 \\
\hline 1900 & 1760 & 3.56 & 2.04 & 3.74 & 2.09 & 2.40 \\
\hline 1999 & 1761 & 2.56 & -.77 & 2.67 & 1.67 & .95 \\
\hline 2101 & 1762 & 2.88 & -1.27 & 2.08 & -.67 & 3.77 \\
\hline 2199 & 1763 & 2.87 & .03 & 2.98 & -1.22 & 3.07 \\
\hline 2304 & 1764 & .35 & -2.26 & .33 & -2.15 & .01 \\
\hline 2400 & 1765 & 1.45 & -1.99 & 2.43 & -2.30 & 1.79 \\
\hline 2450 & 1766 & 1.89 & 1.65 & .84 & -1.23 & .30 \\
\hline 2500 & 1767 & .24 & -1.35 & -1.00 & -2.04 & -.56 \\
\hline 2600 & 1768 & -.29 & -.55 & -1.05 & -1.91 & -1.13 \\
\hline 2700 & 1769 & .98 & -.02 & .43 & -1.07 & -.73 \\
\hline 2743 & 1770 & 2.68 & 3.64 & 1.49 & -1.21 & .92 \\
\hline
\end{tabular}




\begin{tabular}{|c|c|c|c|c|c|c|c|c|c|c|c|}
\hline \multirow[t]{2}{*}{$\operatorname{rpm}(\mathrm{N} 1 \mathrm{CORR})$} & \multirow[t]{2}{*}{ File } & \multicolumn{2}{|c|}{$[0,809] \mathrm{Hz}}$. & \multicolumn{2}{|c|}{$[0,199] \mathrm{Hz}}$. & \multicolumn{2}{|c|}{$[211,398] \mathrm{Hz}}$. & \multicolumn{2}{|c|}{$[410,610] \mathrm{Hz}}$. & \multicolumn{2}{|c|}{$[621,808] \mathrm{Hz}}$. \\
\hline & & low & high & low & high & low & high & low & high & low & high \\
\hline 1622 & 1756 & 3.81 & 5.19 & 2.77 & 6.48 & 3.12 & 6.11 & 2.52 & 5.44 & 3.35 & 5.88 \\
\hline 1703 & 1757 & 4.22 & 5.62 & 2.81 & 5.55 & 3.42 & 6.63 & 2.96 & 6.81 & 2.88 & 6.40 \\
\hline 1750 & 1758 & 3.46 & 4.98 & 2.05 & 4.89 & 3.72 & 5.73 & 1.96 & 5.13 & 1.09 & 5.96 \\
\hline 1800 & 1759 & 3.67 & 5.18 & 1.92 & 4.89 & 2.34 & 5.78 & 2.25 & 5.11 & 1.83 & 6.24 \\
\hline 1900 & 1760 & 3.50 & 4.98 & 2.32 & 4.97 & 3.16 & 5.71 & 1.64 & 7.98 & 1.79 & 7.12 \\
\hline 1999 & 1761 & 2.70 & 4.28 & -.30 & 2.72 & 2.51 & 5.11 & 2.78 & 6.23 & 1.56 & 5.97 \\
\hline 2101 & 1762 & 2.93 & 4.65 & -1.63 & 2.08 & 1.27 & 7.58 & .46 & 4.52 & 3.18 & 8.36 \\
\hline 2199 & 1763 & 3.03 & 4.60 & -.14 & 4.06 & 3.01 & 5.05 & -.40 & 2.72 & 2.93 & 6.28 \\
\hline 2304 & 1764 & .61 & 2.07 & -1.64 & 2.38 & .36 & 2.41 & -1.06 & 2.78 & .14 & 2.68 \\
\hline 2400 & 1765 & 1.70 & 3.53 & -2.06 & 2.24 & 2.58 & 5.46 & -2.22 & 2.14 & 1.73 & 4.23 \\
\hline 2450 & 1766 & 1.77 & 3.52 & 1.24 & 4.62 & .36 & 3.31 & -1.35 & 2.14 & .10 & 3.47 \\
\hline 2500 & 1767 & .49 & 2.07 & -1.53 & 2.73 & -.62 & 2.02 & -1.48 & 2.66 & -.29 & 2.59 \\
\hline 2600 & 1768 & -.57 & 1.51 & -1.15 & 2.46 & -1.27 & 3.29 & -1.50 & 1.86 & -2.54 & 1.25 \\
\hline 2700 & 1769 & 1.43 & 2.86 & -.25 & 4.33 & -.20 & 3.74 & -.84 & 2.26 & -.04 & 2.70 \\
\hline 2743 & 1770 & 2.66 & 4.14 & 3.83 & 6.97 & 1.42 & 4.67 & -1.23 & 2.45 & .50 & 3.29 \\
\hline
\end{tabular}



